Hasan: Semiotic Mediation

\title{
SEMIOTIC MEDIATION AND MENTAL DEVELOPMENT IN PLURALISTIC SOCIETIES: SOME IMPLICATIONS FOR TOMORROW ' S SCHOOLING
}

\author{
Ruqaiya Hasan
}

\begin{abstract}
That children 's learning begins long before they attend school is the starting point of this discussion. Any learning a child encounters in school has a previous history. (Vygotsky 1978: 84).
\end{abstract}

The enormous reach of Vygotsky' s theoretical approach to mental development derives from the very concept of semiotic mediation. What makes the concept so powerful is the fact that it establishes connections across some of the most important areas of human social existence. More specifically, it foregrounds a fundamental relationship between mental functions and discourse within the context of social/cultural activity. This, in turn, invites us to explore the relations between the disciplines of psychology, semiotics and sociology. Reflection on these interconnections suggests that if we wish to fully understand the implications of Vygotsky's claims about the sociogenesis of human mind, then on the one hand we must be willing to ignore the conventionally accepted boundaries erected in the name of specialisation across these and many other disciplines, and on the other hand we must be prepared to probe deeper into the significance of the claims made by this powerful theory

It is well recognised (Vygotsky 1962; Wertsch 1985) that in putting forward the concept of semiotic mediation, Vygotsky attached greater importance to language than he did to other modalities of meaning. We need, then, to ask why language has been granted this special status in Vygotsky's theory; what it is that language enables us to do which other semiotic 
Hasan: Semiotic Mediation

modalities do not -- or at least not to the same extent, or with the same facility. Similarly, in identifying social/cultural activity as the essential site for the operation of semiotic mediation the theory opens up interesting questions, such as the relation between cultural activities and language, and whether different kinds of activities encourage different forms of semiotic mediation. Since the societies we know today are pluralistic, with multiple groupings whose boundaries are drawn by reference to interest, race, gender, occupation and socio-economic status, it is important to ask whether the different social groups engage in the same range of activities, and if so, whether the performance of such activities takes the same form across the distinct social groups.

If there is an inherent relation between language, cultural activities and semiotic mediation, and if we wish to understand the working of semiotic mediation, then we do need to focus on such questions. It seems to me that the extent to which we can benefit from the application of Vygotskian insights depends on how far we are able to engage successfully in enquiries of this kind. Nowhere does this appear truer than in the complex area of constructive thinking on education, both its theory and its practice. It is the aim of this chapter to begin an exploration of the concept of cultural activity in relation to semiotic mediation by using the modality of language. I hope that this exploration will reveal some important implications of accepting semiotic mediation as the essential means of making human minds, and thus suggest avenues for conceptualising better programs for truly egalitarian education.

\section{Semiotic Mediation: One Process, Two Manifestations}

I shall use the term semiotic mediation throughout this chapter as a short form for semiotic mediation by means of the modality of language. The term semiotic refers to all modalities $\mathrm{r}$ 
Hasan: Semiotic Mediation

for signing, not just language. In assigning this crucial place to language in the processes of semiotic mediation, I do not wish to prejudge the role of other semiotic modalities in the formation of higher mental functions, but simply to respect Vygotsky 's own usage (Vygotsky 1978; Wertsch 1985). The term mediation on the other hand refers to a process that is inherently transitive: it requires at least two participants -- something/someone mediates something. So for the purposes of this chapter the term semiotic mediation may be paraphrased as mediation of something by someone to someone else by means of the modality of language.

Using the term in this sense, I take it as axiomatic that semiotic mediation is a constant feature of human social life. The natural condition of language in use in the context of cultural activity is to mediate; the issue is not whether it mediates, but rather what it is that it mediates. In the writings of Vygotsky and his colleagues, as well as in current discussions and applications, it has been customary to invoke the agency of this process with specific reference to concept formation and/or some form of problem solving. The concepts and problems cited belong typically to the specialised educational activities of officially recognised educational sites. To be sure, semiotic mediation is a powerful tool in these processes, but to emphasize its function only in such contexts is to encourage the questionable view that this constitutes the default function of semiotic mediation, that it represents its true essence, and that semiotic mediation functions only intermittently, coming into play in cultural activities which call for explicit, deliberate teaching of specific concepts, knowledge structures and the like. I believe that such a view of semiotic mediation undersells the concept. In fact, to appreciate the full power of this notion, all we need do is to 
Hasan: Semiotic Mediation

remember that semiotic mediation occurs wherever discourse occurs, and that discourse is ubiquitous in the living of social life: semiotic mediation is what language naturally does in discourse. And the most important thing that language does in discourse is to enable the speaking subjects to internalise the world they experience in the living of their life. This includes -- but also goes beyond -- the formation of specific concepts, especially if by the term concept we mean to refer only to technological or scientific concepts, the conscious inculcation of which is taken to be the main aim of formal education.

Seen from this perspective, the most basic and foundational achievement -- but certainly not the only achievement -- of semiotic mediation is the inculcation of mental disposition, that is to say, the habits of mind, tendencies to respond to situations in certain ways (see Carr, and also Claxton, this volume), producing in social subjects a sense of what things are worth doing in their community, and how they are to be done. The claim that this is the most fundamental aspect of the development of the human mind is in keeping with Vygotsky ' $\mathrm{s}$ framework, where concept formation is not a passive, receptive process; rather, it involves the active participation of the learners in their learning. By this logic, the learners ' mental dispositions, their readiness to engage in the appropriation of some concepts rather than others, as well as the mode of negotiation they habitually bring to the learning situation, would constitute the foundation on which the edifice of the semiotic mediation of specific concepts, and of specialised knowledge structures of one kind or another, can be erected (however, see below under Concluding Remarks for certain important qualifications to this view). What this claim means is that the 'tendencies to respond to situations in certain ways ' are as relevant in the context of educational learning as they are elsewhere in everyday $\mathrm{r}$ 
life.

There are good reasons for attending to the differences between these two modes of the operation of semiotic mediation, one mode that creates the 'habits of the mind ' -- a sense of relevance which is active in the social subjects of actions and/or negotiations, furnishing motivations for engaging in them or not -- and another that leads to the appropriation of the elements and structures of specialised knowledge. I will refer to these two manifestations of semiotic mediation as invisible and visible mediation, respectively. As the label suggests, visible mediation is deliberate and relatively more clearly focussed on some specific concept or problem: interactants can actually ' see' what they are doing. Speaking cautiously, at least one of the interactants is aware that s/he is teaching or explaining something specific to someone; further, an essential requirement for success in learning is voluntary attention and active participation on the part of the learner. In this way both interactants have a fairly clear sense of the goal to be achieved. This is in contrast to invisible mediation where interactants are aware of neither the teaching nor the learning of any concept in particular, much less of any specific goal to be achieved -- or, at least, the goal uppermost in the mind is not directly relevant to what language is mediating. The interactants do not 'see' what is being mediated; what they 'see' is some process of everyday living which furnishes the occasion for quite mundane discourse such as the following:

Extract 1.1:

Mother:put it up on the stove and leave it there

Karen: $\quad$ why?

Mother: cause

Karen:

that ' $\mathrm{s}$ where it goes? 
Hasan: Semiotic Mediation

The normal reaction to such discourse is that nothing is happening which could be considered significant from the point of view of mental activity. I will show later that this is not the case, that in fact important elements of mental disposition are being mediated. This is why I have chosen the term invisible for such mediation. Mediation of this kind is naturalised in the sense that at least one of the interactants, the one who is already well versed in the ways of her/his community, treats the sayings and their meanings as entirely natural, as if no other form of behaviour is possible. The important fact is that other forms of behaviour do exist within the same society: it is simply the habits of the mind that make one think otherwise. Together these forms of semiotic mediation serve important purposes in the creation of culture on the one hand, and in preparing social subjects to live with a lived sense of belonging to the culture in which they are located: the latter is of course a condition for the maintenance of culture.

However, I would suggest that from the point of view of the development of an individual, invisible mediation is primary, both in terms of time and in terms of its pervasiveness, because it begins from very early infancy, and it occurs across a large number of cultural activities. Because invisible mediation starts early in life, because it is instrumental in creating ' habits of the mind ', and because habits of the mind are crucial to a subject 's ways of engaging in visible semiotic mediation, it is reasonable to suggest that visible mediation is not entirely independent of invisible mediation. To appreciate these points, we need to examine language as it operates in the context of a variety of cultural activities. In the following sections I will discuss examples of natural, spontaneous discourse to support the $\mathrm{r}$ 
Hasan: Semiotic Mediation

claims I have been making. These examples are taken from naturally occurring dialogues between mothers and their young children, which formed the data base for a sociolinguistic research project I conducted with a view to examining The Role of Everyday Talk between Mothers and Children in Establishing ways of Learning ${ }^{\text {ii }}$.

\section{Semiotic Mediation and Cultural Activities}

The two modes of semiotic mediation identified above are typically associated with distinct contexts of cultural activities. The qualification 'typically' is important, because human activities vary along several dimensions, and these dimensions cut across each other, thus creating a large number of activity types, each of which differs from the others in some respect. It is not so much some specific category of activity that is in question but rather some specific properties of the activities in question. Due to lack of space I will be concerned here only with two dimensions for activity classification. First, there is the dimension that I have referred to as the sphere of activity (Hasan 1999) $3^{\mathrm{ii}}$. Cultural activities range from everyday, ordinary ones to those that are highly specialised. Everyday activities extend over a whole cultural community. Because of their ubiquity, they appear entirely ordinary and unremarkable; in fact most are so basic to the living of human life that we may think of them as universal. To cite a few examples, humans everywhere go about the business of preparing and eating food, minding their children, getting their cleaning, their washing and shopping done, and equally importantly they take steps to indicate that they are members of their local 'village' (Lemke, this volume), though of course the details of how they do these things vary to different degrees across cultures and subcultures. However, what is in common is the fact that everywhere the conducting of these activities becomes highly 
Hasan: Semiotic Mediation

routinised, scarcely requiring concentrated attention. As members of a (sub)culture, we know how such activities are done; everyone around us is doing them, and in our turn, we too just go ahead and do them effortlessly. Even if we happen to be individualists, devoted to the virtue of originality, it is just not cost effective to invest time and energy in rethinking from the ground up how we as unique individuals should go about such activities. It is in this absence of conscious reasoning about why and how one step in the activity should follow another, it is in this absence of the need for elaborate planning of how an everyday activity should be brought about, that the power of these activities resides. Familiarity breeds invisibility: we fail to even notice that we are engaged in any activity.

By contrast, specialised activities do not extend over the whole community. One manifestation of the division of labour in society is precisely that certain activities are typically performed by certain social groups and not by others. Activities of the professional type such as lecturing, welding, banking are clear examples. And though in some cases, especially where the activity is physical -- welding would be one example -- the various actions in its performance can become routinised, specialised activities typically require reflection on how they are to be performed: for example, no amount of experience in lecturing ever means that we can lecture more or less on auto-pilot! And in all cases, the actants are aware of the endpoint of the game they are engaged in.

Cutting across this dimension is the dimension of the form of action. Here two major forms to note are acting by doing -- material action -- and acting by saying -- verbal action. There are times when the interactants ' action may be entirely material, i.e. it may be carried 
Hasan: Semiotic Mediation

out physically, such as when mowing the lawn, or it may be entirely verbal, carried out purely linguistically, such as when talking on the phone, conducting a seminar, participating in a talk-back radio program etc. But very often both material and verbal actions co-occur spatio-temporally. This co-occurrence can be of different kinds, and two are particularly relevant to the present discussion, since they have different significance from the point of view of cultural activity -- one where the verbal action is ancillary to the material action: that is to say, language is used in aid of performing the material activity, and the other where verbal and material action run side by side without either being relevant to the other, as in discussing linguistics while having a snack. In the first case a single cultural activity is at stake, while in the second, strictly speaking, two activities are being performed in parallel, one material, the other verbal. It is important to recognise that in real life as opposed to in academic analysis there is no readily obvious punctuation, no clearly demarcated division between one activity and the next: distinct activities weave in and out of one another and sometime there may be no indication of a shift from the context of one activity to that of the other except that provided by the language of the text. Consider the following example taken from an interaction between mother and Helen ( 3 yrs $11 \mathrm{mths})$ as they wash and dry up dishes:

\section{Extract 2.1:}


Helen: the dish .. The dish first .. dinner to get tonight

Helen: $\quad$ what kind of dinner?

Mother:we ' 11 have a roast leg of ham

Helen: $\quad$ goody!

Mother:and roast vegies

Helen: $\quad$ goody!

Helen: goody!

Mother:he ' $\mathrm{d}$ like a nice feed of peas

Helen:

$[?]$ that?

Helen: $\quad$ yeah, goody! I' 11 make it for you

In turns 1-4 of this extract, verbal action is assisting in the conduct of the on-going material activity of washing up: this is the ancillary use of language, and at this point only one activity is being performed. However, at turn 5, a shift (Hasan 2000) occurs as the new topic of dinner is broached, and this shift is con/textual: that is to say, it is a shift in the text as well as in the context of the text ${ }^{\mathrm{iv}}$. Turns 6-16 constitute a discussion of that evening 's dinner. So at this point, side by side with the on-going material activity of washing up, we have the verbal activity of discussion running in parallel with the material activity of washing up. The activity of discussion is entirely constituted by language: the verbal action is not ancillary but $\mathrm{r}$ 
Hasan: Semiotic Mediation

constitutive of discussion. This suggests that the identity of cultural activities is not given by their spatio-temporal location, but by the mode of their realisation; if two persons are washing up, it does not follow that everything that is said during that time in that place pertains to the activity of washing up. Similarly, one may begin with an everyday activity such as getting lunch for one' s child, but end up with two parallel activities, one of getting the lunch and the other the specialised activity of explaining about the food chain (see below). I shall return below to the significance of con/textual shift for semiotic mediation.

In the above extract, the discussion in 6-16 moves around in the general domain of things concerned with food, but it is not necessary for the two parallel activities to share the same domain. When a constitutive verbal activity runs parallel to some everyday material activity, the talk will quite often move to topics not at all related to the on-going material activity. Thus it was during one such activity of washing up that Helen and her mother had the following interaction. Helen was washing up a saucepan lid which apparently needed a good deal of scrubbing, and the mother was guiding Helen ' s washing up of the lid:

\section{Extract 2.2:}

1

2

3

4

5

6

March 2001
Helen: $\quad$ you have to do it hard, don ' $t$ you/?

Mother:mm, you do, don 't you, yes ...

Helen: doesn ' $t$ matter for you and me to do these

Mother:no

Helen: because we can do it the right way, God teaches us

Mother:no, God doesn ' $t$ teach you things like that, it 's

mummy' s job to teach you things like that 
The mother's comment in the last turn It's mummy's job to teach you things like that is very far removed from the business of washing up. As an adult well versed in the ways of her culture the mother is voicing one of the perceived ways of managing life in her community: she is telling her daughter explicitly about an expectation attached to being a mother. Casual conversation abounds in such explicit aphorisms. The fleeting appearance of an utterance of this kind, which represents the distillation of some communal experience, hardly reaches the point of conscious deliberate reflection, which would be typical of a sustained discussion on the same topic such as one might encounter in an educational setting. Had the interactants been asked what they were doing, they would have said they were just washing up, not that one was teaching the other about communal expectations attached to certain social locations.

However, over time, talk of this kind occurring again and again constructs a design for ways of being, doing and saying that are viewed as legitimate within the speakers ' community. In this sense, such discourse is a site for one kind of invisible semiotic mediation: what it mediates is elements of mental maps for living in the culture of one 's immediate community. This kind of semiotic mediation typically occurs in the course of everyday physical activities precisely at the point where a con/textual shift turns the verbal action briefly from ancillary to constitutive. Given the definition of semiotic mediation offered above, it follows that, for all cases of semiotic mediation, verbal action must be present whether physical action is or not.

Such explicit teaching, what Bernstein $(1990 ; 1996)$ referred to as local pedagogy ${ }^{\mathrm{v}}$, occurs frequently especially in the discourse of adults and children. It certainly has an important 
Hasan: Semiotic Mediation

place in the child 's mental development, and I shall discuss some more examples of such mediation later. But invisible mediation does not consist wholly or even largely of observations and aphorisms which explicitly present the distilled experiences of the community. The much more powerful instrument for the formation of mental habits is furnished by verbal action that cooccurs with everyday physical activities, whether this verbal action is ancillary, as in turns 1-4 of extract 2.1 , or constitutive, as in the rest of that extract. The difference between the discussion of dinner plan in 2.1 and the aphoristic saying in extract 2.2. is simply that the latter explicitly invokes a cultural convention, whereas the other segments concern something purely local to the here and now of the specific speakers.

What is most relevant to the production of mental habits is the ways of saying and meaning, where no cultural rules are being explicitly enunciated. This does not mean that culture is irrelevant to these encounters; it is simply that it goes underground: sayings of all kind depend largely on taken-for-granted ' truths ' -- truth whose basis is not contested but is treated rather as self-evident. It is this experience of the facticity (Berger \& Luckman 1971) of the world that underlies everyday discourse in which young children participate ordinarily and naturally every day of the week, every waking hour of the day, which in its turn produces in children an understanding of what their social universe is like, what ways of being, doing, saying, and even thinking, are favoured by those in their immediate social group. The appropriation of a certain set of mental habits is not so much the result of explicit injunctions, therefore; rather, it is nourished by sayings which scarcely seem to say anything significant -- for example sayings of the kind presented in extract 1.1. Everyday activities are the most hospitable environment for such sayings, because in the nature of things, everyday 
Hasan: Semiotic Mediation

activities neither require nor allow the opportunity for deliberation. Their near

automatisation, their unquestioned, almost unquestionable rationality for social subjects already initiated into the culture leads to an absence of reflection, to the certainty that what one is saying and/or doing is the most rational, the most normal thing to say and do.

Mental dispositions come about in the primary experience of internalising the implications of meanings worded by speakers un-self-consciously in precisely such environments. To exemplify such talk, I quickly present a brief and partial account of the sort of things mothers say to their children while engaged in some everyday material activity.

Take, for example, a mother who might ask her child did you know that they are going to leave? There is nothing extraordinary in someone uttering such a question: people ask such questions all the time, but consider with some care what it is that the mother has actually done. She hasn ' $t$ asked to be informed of some state of affairs that is unfolding in the world; she hasn ' $t$ asked if something is the case in the world. Her concern is to find out the mental state of her child -- what the child knows. I have referred to such questions as prefaced questions (Hasan 1989). There is a difference between are they going to leave? and did you know that they are going to leave? The latter, which is a prefaced question, asks the addressee not about what is or is not going on in the world, but about the addressee 's state of knowledge: did the addressee know something to be the case. The asking of such a question carries certain implications: first, it implies that knowledge about the child 's mental state is not available to the mother unless the child explicitly tells her. To many of us, this is a selfevident fact; we believe it is entirely natural for us not to know other people 's mental state

r 
unless they choose to inform us. However, below I will discuss examples (see 4.1 and 4.2) which suggest that this belief is far from universal.

For the moment, let me pursue the chain of implications following upon a prefaced question. If you happen to believe that anothers ' mental state is unknowable without the use of language, this in turn implies that language would be treated as the essential bridge spanning two individual minds. That being the case, one would expect such speakers to habitually use language so as to make the meaning of their messages as precise as possible. In most languages, the way to do this is to qualify the state of affairs, specifying its manner, location, time etc. Further, because language is seen as an important means of getting to know the other, it follows that others ' questions must be attended to; comments and assertions must be heeded, answers should be provided that address the query point. In the analysis of some 2008 maternal questions and their answers, we found that the mothers who habitually asked prefaced questions were also the ones who asked highly qualified questions, and provided highly developed answers. Consider the following example:

\section{Extract 3.1:}

1

2

3

4

5
Mother: did you know that they are going to leave?

Kristy: no

Mother:they 've been building a house

Kristy: $\quad \mathrm{mm}$

Mother: oh they haven't been building it, somebody else has been

building it for them, and it 's nearly finished, and they ' re going to move to their house in May r

March 2001 
Kristy: $\quad$ why in May?

Mother:they ' re going to wait until the end of the school term

Kristy: $\quad \mathrm{mm}$

Mother:because Cathy goes to school now, and then she will

Kristy: $\quad * * m m$ see, it would mess it up a bit for her

Note how the mother is careful to clarify the sense of her claim that they 've been building a house, something that at three and a half years of age Kristy might well have misinterpreted. Note also how in response to Kristy' s why?, she meticulously lays out the reasoning behind her friends ' decision to move to their new house in May, not earlier. The mothers who ask prefaced and qualified questions, in their own turn hardly ignore the questions asked by their children, and overwhelmingly offer relevant and developed answers, rather than minimal ones. There is significant statistical proof from my research as well as that of Williams (1995) that the massive experience of engaging in discourse of this kind produces in the children a particular kind of orientation to meanings, a certain habit of mind, a tendency to respond to questions and to information in ways that are qualitatively different from those of children whose mental habits and whose experience of everyday discourse is different. To appreciate how different the experience of discourse is for this other group of children let us take a look at the following: 
Extract 4.1:

\section{Extract 4.2:}

1

2

3

4

5

6

7

8

9

10

11

12
Karen: $\quad$ how did you get that?** you didn 't get out of [?]

Mother:I walked over and got it, didn' $t$ I?

\begin{tabular}{|c|c|}
\hline \multicolumn{2}{|c|}{ Mother: d ' you love daddy? ... d ' you love daddy } \\
\hline Julian: & mm (AFFIRMATIVE) \\
\hline \multicolumn{2}{|c|}{ Mother: d ' you love Rosemary ${ }^{\mathrm{vi}}$} \\
\hline Julian: & no \\
\hline \multicolumn{2}{|c|}{ Mother: why don ' t you love Rosemary? } \\
\hline Julian: & (LAUGHS) \\
\hline \multicolumn{2}{|c|}{ Mother:why don ' t you love Rosemary? } \\
\hline Julian: & (CONTINUES TO LAUGH) \\
\hline \multicolumn{2}{|c|}{ Mother:you ' re a rat-bag (REALISES THAT JULIAN WAs } \\
\hline & TEASING) \\
\hline Julian: & I do \\
\hline Mother: [? & ] \\
\hline Julian: & who else do you want me to love? \\
\hline
\end{tabular}

In these extracts the mothers ask what I have called an assumptive question. Such questions are realised grammatically by a negative interrogative. I call these questions assumptive (Hasan 1989) because the person asking such a question, appears to have already made an assumption what the correct answer ought to be. In extract 4.1, the mother 's expectation is that the answer to didn 't you see me? should be yes I did, otherwise you must be blind, and r 
Hasan: Semiotic Mediation

we know that Karen is not blind: the mother assumes that had Karen been behaving according to normal expectations, she would have seen her mother go out to get the object. In extract 4.2, the mother' s question why don 't you love Rosemary? assumes that, as a normal brother, Julian ought to love Rosemary. It does not seem far fetched to suggest that mothers asking such questions assume they know what their child 's mental state is. Julian understands this as is clear from his message in turn 12, which we may paraphrase as: it is clear to me by your ways of questioning that you think I should love Rosemary, this implies that you also have views on who else I should love; so who are those people that in your opinion I should love?

It is perhaps obvious that assumptive questions are the converse of prefaced ones. If a mother habitually asks assumptive questions, she implies that she knows her child' s mental state: she knows what her child knows, what s/he feels or senses. In an important sense the child $=\mathrm{s}$ answer is irrelevant; the mother already knows without explicitly being told. This in turn implies that language has a less critical status in the establishment of the creation of intersubjective relations between them. Interestingly, mothers who are very frequently ask assumptive questions, are also relatively less concerned about attending to their child ' $\mathrm{s}$ question; they also put in less effort into making their questions precise or their answers developed; in fact, minimal and what one might think of as inadequate answers are quite likely, as exemplified in extracts $3.3 \& 1.1$ :

\section{Extract 4.3:}




$\begin{array}{ll}2 & \text { Pasan: Semiotic Mediation } \\ 3 & \text { Mother:yes he is } \\ 4 & \text { Pete: whe won ' t come home } \\ 5 & \text { Mother:he ' s coming home this afternoon } \\ 6 & \text { Pete: } \quad \text { Mother:yeah, he ' ll get it this afternoon } \\ 7 & \text { Pete: } \\ 8 & \text { Mother:oh a long time }\end{array}$

What I am suggesting is that sayings as trite as the exchange 'why?' ' Cause' are not without importance in the formation of mental attitudes. It is a commonplace that questions are a way of finding out, but perhaps one 's experience of discourse might discourage the formation of this attitude to questions.

This reading of the extracts might provoke the comment that what we have here is a case of overkill, that too much is being claimed on the basis of very little evidence. And the reaction would be justified if the case were built only on the strength of a few isolated examples. However this is not the case. First the extracts cited above are representative of a much larger corpus; further the main thrust of the finding has been validated by results achieved in other related researches carried out by other colleagues $1^{\mathrm{vii}}$. And second, the semantic features I have picked out above form part of larger clusters, and their pattern of occurrence tends to differentiate significantly the speech of the two groups of mothers. The elements of these semantic clusters are logically/implicationally related to each other since a semantic feature, being purely relational, carries within itself some implication of what other semantic features may or may not ' reasonably' and ' rationally' keep company with it without r March 2001 
Hasan: Semiotic Mediation

jeopardising communication. This means that the children have a massive experience of certain specific ways of saying and meaning, which are characterised by a particular semantic direction. Participation in this discourse shapes the children 's consciousness, orients them to taking certain ways of being, doing and saying as legitimate and reasonable; in short, it defines the contours of reality and provides a map for navigating that reality.

There is consistent and strong evidence that, at this early stage of three and half to four years, the children belonging to these two groups have established different ways of learning, different ways of solving problems, different forms of consciousness, or mental disposition. This evidence comes from an examination of these children 's talk in three environments: (i) talk with their mothers in the same everyday environments, (ii) their negotiations with familiar neighbourhood peers during spontaneous play, and (iii) their discourse in the classroom during the first few weeks after entry into the school at around the age of five. True that the patterns of language I have singled out are very ordinary. But this, in a way, vindicates the claim that the production of mental disposition is brought about by the invisible semiotic mediation of un-self-conscious discourse which is embedded in everyday cultural activities. Such discourse is ordinary; and that is why it is so effective. As this process begins from early infancy, invisible mediation which occurs in the course of everyday activities as described above attains a primary status in the life of the individual. It becomes in effect the ruler of attention and interest, of motivation and relevance. The child 's ways of participating in the negotiation and appropriation of technical concepts or specific knowledge structures, etc. is coloured initially though not necessarily finally by the experience of this primary mediation.

r 
Before leaving this section, it remains to point out one very important feature of this mode of semiotic mediation which is instrumental in producing primary mental disposition. The discourse that lends itself to this function is embedded in everyday cultural activities. These activities are overwhelmingly culture maintaining, since their efficient performance depends on routinisation, which means a suspension of reflection. This encourage the tendency towards preserving existing templates. Thus each of the two groups of mothers semiotically mediates precisely the ways of being, doing and saying that come naturally to them, that are their ways of coping with everyday reality. Through this mediation, the mother's culture becomes the growing child' s map of reality, thus ensuring its own continuance. One way that this cycle of cultural reproduction can be given a different shape is through the working of visible semiotic mediation, to which I turn below. Although the sites par excellence for the operation of visible semiotic mediation are acknowledged to be schools and universities, for lack of space I will be concerned here only with visible semiotic mediation at home. This will allow us to see the different histories of semiotic engagement that children bring to the school.

\section{Semiotic Mediation, Higher Mental Functions and Specialised Cultural Activities}

Consider the following extract that is taken from a very lengthy discussion between Kristy and her mother. The origins of this dialogue go back to an earlier scene where Kristy was having a meal. At that earlier point, a little moth had just died a soggy death by flying low over a steaming cup. Kristy was distressed by this death:

r 


\section{Extract 5.1:}

1
Kristy: $\quad$ why did he die there?** why did he die there?** $\mathrm{He}$ wouldn ' $t$ have wanted to die, do you know that? Mother: that ' s right, most things don ' $\mathrm{t}$ want to die Kristy: $\quad \mathrm{mm}$, a dog will get killed by something that wanted to eat a doggie

Mother:yeah, sometimes people want to die, or animals want to die if they are very sick and it ' s hurting them

Kristy : $\quad \mathrm{mm}$

Mother:but yeah, usually animals and people don ' $t$ want to die, so -

Kristy: $\quad \mathrm{mm}$

Mother: everyone has to die sometime, and sometimes people or animals have accidents

Kristy: $\quad \mathrm{mm}$

Mother: or sometimes other things eat them, so other moths get eaten by birds

Kristy: $\quad$ why do they?

Mother:well, birds need to eat **and -

Kristy: $\quad * *$ yeah and -

Mother:mm?

Kristy: they [? should ' ve] eat bigger things um mice

Mother:you think birds should eat mice?

Kristy: $\quad$ yeah

Mother:well, you got upset the other day about the eagle at the 
museum eating the rabbit didn ' $t$ you?

19

$$
\text { Kristy: } \quad \mathrm{mm}
$$

Mother:see, there ' s not much difference is there? I think you just don ' $t$ want the moth to get eaten do you?

$$
\text { Kristy: no }
$$

Mother:well -

Kristy: he didn ' $t$ want to die?

Mother:no ..

Kristy: that 's [?broken] .. Ruth teared it

Mother:she what?

Kristy: $\quad$ teared

Mother:oh it 's OK

Kristy: why' $\mathrm{s}$ it OK?

Mother:Peter just brought it home for me to have a look at, but he didn ' $t$ need to keep it

Kristy: $\quad$ why didn ' t he?

Mother:oh! oh, I don ' $t$ know (LAUGHS) I don ' $t$ think he needed to keep it .. he ' d probably read it already

Kristy: why he probably read it already?

Mother:um, I think if he had wanted to keep it and he needed it, he would have told me to put it somewhere safe, but he put it there which is the place where we put stuff we don ' $t$ really care about, that ' $\mathrm{s}$ why I think that he didn ' $t$ need it, either he had already read it or he didn ' $t$ want it Kristy: why did the eagle eat the rabbit? 
Mother:because rabbits are the sort of animals that eagles eat, different animals eat different food, they they eat food that lives where they can catch it and food that 's the right size for them to catch

Kristy: $\quad \mathrm{mm}$ big, but eagles can eat rabbits, they ' re a nice size for eagles, they give them plenty to eat, and they ' re small enough for eagles to catch, but most animals eat other animals, even you eat chickens and every time you eat a chicken a little chicken has to die

There is much more of this discussion but we can stop at this stage of what is surely a model lesson on the grim rudiments of natural selection. I would like to use this extract to draw attention to some important points. First, compare this with extract 2.2. In both cases the discussion runs parallel to some other everyday material activity, and it goes without saying that the verbal action is constitutive. There are however some major differences between them: in extract 2.2 , the move into the constitutive is evanescent, hardly receiving conscious attention, whereas in 5.1 the constitutive activity of discussion is much more developed. Had the mother been asked what she was doing, very likely she would have said that she was explaining to Kristy why every living thing has to die some time, and how in order for one thing to live another thing might have to die. In 2.2 , the aphoristic comment is a putative beginning of a specialised activity of explaining about maternal obligations, whereas in 5.1, the activity of explanation is full fledged. This too is a case of local pedagogy, but unlike 2.2 
Hasan: Semiotic Mediation

it displays a more deliberate and sustained effort at 'getting some point across' and at the same time it makes contact with a fragment of educational knowledge. In short running parallel to an everyday cultural activity, we have an instance of a specialised one. This local pedagogic activity is not exactly like a lesson in a classroom, but it is as close to that activity as you can get at home, especially where one participant is relatively immature. This is a thus a classic example of visible semiotic mediation, which occurs by means of discourse embedded in specialised cultural activities calling for sustained attention by participants.

As pointed out before, specialised cultural activities, unlike the everyday ones do not extend over the whole cultural community. There is an interesting paradox here: everyday activities are near universal, though the way they are carried out varies across different communities, and in this sense, these near universal activities are essentially localistic in their manifestation. By contrast, specialised cultural activities are restricted in their distribution within a culture: not everyone engages in them, though wherever a category of such activity is found, the form of its manifestation is near universal. Specialised activities depend fundamentally upon verbal action; and very often, they enlist other semiotic modalities in their performance, for example, figures, images, charts, scale models, logical and mathematical symbols, ritual representations of superhuman forces, etc. are instances of nonverbal semiotic modalities pressed into service as abstract tools for the semiotic mediation of ' uncommonsense' concepts and knowledge structures.

For most of us today, by far the most common specialised activities are those experienced regularly in schooling. At least in the so-called advanced societies, for decades the school 
Hasan: Semiotic Mediation

has been the major official site for the production and distribution of such knowledge. But it is really at home that the ontogenesis of what Claxton (this volume) calls epistemic mentality takes its first halting steps. Mercer (this volume) presents an example of such an interactive episode, and my data too provides rich support for making this claim. However, with my colleagues, Cloran $(1994,1999)$ and Williams (1995, in press), I find that the occurrence of such interactive episodes is selective: it is not children, as a general category, but some children belonging to a particular group, who typically experience discourse of this kind -- as a comparison of 5.1 with $5.2 \mathrm{a}-\mathrm{c}$ will confirm.

Let me turn now to another important point about 5.1; this concerns the movement of the discourse: we note that at turn 25 , Kristy' s attention is diverted by some magazine page that Ruth, her baby sister, had torn up. She probably expects her mother to share her concern, and as her mother disappoints this expectation, she wants to know the reason for the mother 's lack of concern. This sets off a chain of explanations. When Kristy's need to know has been satisfied, she turns once again to the question of why one animal eats another. We note a con/textual shift at turn 25. Although the action in both cases is entirely verbal, and although this verbal action in both cases is constitutive of the activity, they belong to different spheres: turns 25-34 represent an explanation of an everyday event, while the discourse surrounding it concerns themes of mortality, of survival, of life cycles of moths, and of how the life and death of each organism in this world impinges on the life and death of the others: in short, it is the stuff of specialised discourse.

Extract 5.1 is representative of how discourse between mothers and children moves in one $r$ 
Hasan: Semiotic Mediation

group. Time and time again in my data, the discourse of qua-si specialised knowledge occurs in the ' middle of' daily activities, and by necessity it calls for a readiness on the mother' $\mathrm{s}$ part to entertain contextual shifts, to be willing to reclassify the context of the on-going discourse (Cloran 1999; Hasan 1999, 2000). The tendency to move with the child 's moving discourse, the readiness to re-classify context is a discourse characteristic of the same group of mothers who frequently ask prefaced questions made precise by qualification, and who attend to their children 's questions, and provide them with well developed answers. This is evident not only from the examples provided in the section above but also from the last extract. By contrast, the second group of mothers are significantly less willing to entertain contextual shift. Extract 5.2 presents one such instance:

\section{Extract 5.2a:}

Mother: come on, eat your tea please ..

Karen: $\quad$ could you put some more ${ }^{\text {viii }}$ in there? ..

Mother:(WARNINGLY) Karen! .. give me it, eat your tea

Karen: $\quad[? \quad]$

Mother: $\quad \mathrm{mm}$ ?

Karen: [?put] lemon in it

Mother:well, eat some tea, or you don ' $t$ get nothing

Karen: I see how many [? ] there are (TALKS TO HERSELF

\section{AS MOTHER POURS DRINK)}

Mother:quick .. want the lid on it?

Karen: $\quad$ no

Mother: come on, eat your tea, less drink and more eat .. did you 
Hasan: Semiotic Mediation

hear what I said Karen?

12

Karen: $\quad \mathrm{mm}$

Mother:well, do it

As Karen still persists in turning a tea-eating situation into one of imaginative play, of discussion of matters not directly dealing with the business of eating tea, the mother's unwillingness to make such a shift becomes more and more obvious. Within a matter of seconds this same interaction continues as follows:

Extract 5.2b:

1

2

3

4

5

6

7

8

9

10

11

12

13

14

March 2001
Karen: $\quad$ mummy that haven ' $t$ got no sauce on it

Mother:oh you ' ve got plenty of sauce there now, now eat it

Karen: on here

Mother:oh there 's plenty of sauce on your plate Karen, you

don ' $t$ need it on every single drop of tea

Karen: eh?

Mother:you don ' $t$ need it on every little bit

Karen: $\quad[?$ of tea $]$ ?

Mother:mm

Karen: $\quad$ is that [?tea]?

Mother:that 's sauce

Karen: $\quad$ mm hot sauce

Mother:no, mint sauce

Karen: $\quad$ mince? .. why do you put mince sauce on here for?

Mother: ' mint ' not ' mince ' 
Karen: $\quad$ mint, this mint?

$16 \quad$ Mother: use your spoon or your fork

$17 \quad$ Karen: ' Country Practice ' is on now?

$18 \quad$ Mother:no

$19 \quad$ Karen: ' Sons and Daughters ' ?

$20 \quad$ Mother:no, the news

$21 \quad$ Karen: oh ..

22 Mother:that 's why I said use a spoon .. now sit up, and use a

spoon

Extracts 5.2a-b are fairly typical of this group of mothers, who appear to have a well defined idea of the boundaries between contexts, and are normally reluctant to permit the interpenetration of one context by another. If I understand Claxton (this volume) right, it would seem that the two groups of mothers belong to the two distinct cultures described by Edward Hall as monochronic and polychronic cultures. Karen 's mother belongs to the group that, at least in this respect, may be said to have a monochronic culture. In this twenty minute recording of the meal time discourse, the mother produces 20 injunctions to the daughter to ' eat her tea '; she studiously ignores any opening of the discourse in directions other than those specifically pertaining to the meal time activity. In characteristic fashion questions are disposed of with an alacrity that misses their real query point (see for example the mint/mince discussion); and the mention of the TV soapies Country Practice and Sons and Daughters receives short shrift! But does this mean that in such cases, there is no con/textual shift, no reclassification of context at all? As Bernstein (1990) perceptively $\mathrm{r}$ 
remarked, the maintenance of the boundary between categories requires the exertion of power and control. Our example here is no exception. Elsewhere I have claimed (see Hasan 2000) that the context does shift, but the direction of its shift is quite predictable: in order to preserve what she considers to be the boundaries of this activity, Karen ' s mother' s discourse moves resolutely into the regulative mode, as shown by extract $5.2 \mathrm{c}$ which occurs some 3 seconds after extract $5.2 \mathrm{~b}$ :

\section{Extract 4.2c:}

1

2

3

4

5

6

7

8

9
Mother: give me your spoon, and I ' ll feed you, like a big baby, come on, baby! give me your spoon

Karen: $\quad$ (SCANDALISED TONE) no

Mother:well sit up properly, and eat your tea .. Karen!

\section{(WARNING TONE)}

Karen: $\quad$ I' $\mathrm{m}$ falling down (i.e. OFF THE CHAIR)

Mother:you ' re not falling down

Karen: $\quad$ yes I am, I always fall down ...*I am falling down

Mother:**eat your tea

Karen: $\quad$ I am falling down

Mother:sit up, before I get a stick and smack you

If con/textual shift is an invariable condition for moving from the quotidian to the specialised discourse at this early stage in the child ' s life, clearly the reluctance to allow such shifts is likely to have significant consequences for the ontogenesis of specialised discourse.

r 
Turning to a related point, in my data, children 's discursive style was not distinguished by the kind of questions they asked. Thus, quite often they will seek explanations, as did Kristy, but the response the second group of children receive is markedly different from the sort of reasoning favoured in specialised discourse. Consider the following, where the mother is putting Sam to bed (Valentine is Sam 's pet budgerigar):

\section{Extract 5.3:}

1

2

3

4

5

6

7

8

9

10

11

12

13
Mother:he can hear you when you say ' Goodnight Valentine'

Sam: where is he?

Mother:in the kitchen

Sam: what 's he doing in there?

Mother:he 's going to sleep

Sam: huh?

Mother:and mummy 's going to turn the lights out

Sam: $\quad$ why?

Mother: $\quad$ it 's dark

Sam: $\quad$ why?

Mother:it 's night time, it 's ready for bed

Sam: $\quad$ why?

Mother: cause it is, when you wake up in the morning we ' 11 have

our breakfast

If the primary mental disposition is friendly to an un-self-conscious preservation of the cultural templates, as I argued above, one question is what are those templates like, and 
where would their preservation take those practising subjects? The extracts I have presented suggest that the cultural templates for the two groups are significantly different, and they are significantly different particularly from the point of view of what they imply in the context of schooling. The final section consists of a brief word on the implications of this situation and offers a suggestion for an approach to schooling that might go some way towards the ideal of equal opportunity.

\section{Schooling for Tomorrow: Concluding Remarks}

In the preceding two sections I have attempted to show that "any learning a child encounters in school has a previous history." It seems to me beyond doubt that this history favours children differentially in today's industrialised pluralistic societies. The pre-school learning history of the first group of children favours an easier engagement with the specialised discourses of the school; by contrast, for those of the second group, it favours easier adjustment to the regulatory aspect of the pedagogic discourse. To the extent that the real aim of education is to enable pupils not to reproduce knowledge, but to produce it, not simply to replicate but to create, this appears to place the first group in an advantageous position. Educational systems claim to provide equal opportunity for all to acquire the competence for engaging in specialised activities; but this remains an ideal goal, as yet never achieved in reality, anywhere. It would be a simplification of the complexities of the educational system to claim that the only reason it fails to achieve its ideal goal is the differential learning history of the pupils; but that this is one major reason for the schools ' failure cannot be denied. To accept this is not to imply that the learning the child brings to the classroom is final, that the forms of consciousness, the mental dispositions are graven images which are no longer 
Hasan: Semiotic Mediation

susceptible to the very instrument of semiotic mediation which has produced them in the first place. As complex self-organising systems, human brains learn by learning; there is as Wells (this volume) points out a spiral of learning. But an initial effort is required to create a situation in the classroom which recognises the nature of the challenge to draw all children into the activity of learning. The challenge is that those for whom the educational system is ostensibly designed bring many voices into the classroom; however, even a cursory look at classroom practices reveals that it privileges one single voice. This happens to be the voice of the more powerful segment of the society. Those who do not recognise this voice, cannot truly participate in the specialised discourse of knowledge production, and must strive on their own to master this other epistemic dialect.

In the continuation of my research, in which these children were followed into the first year of schooling, we found that across the spectrum of schools the teachers showed no significant variation in their ways of saying: the variation in the data was totally accounted for by the difference in how the children talked during lesson time. The challenge for tomorrow 's education is to correct this situation. And one way of achieving this is to encourage pupils to question the taken-for-granted realities. By this I mean both the reality cherished by the mothers of the first group as well as that cherished by the second group. It is often pointed out that in the classroom it is the teacher who asks questions; I have no objection to this situation so long as the teacher knows how to respect answers -- to respect them to the extent of actually involving their pupils in reflecting on the assumptions that underlie the answers, and involving the child in articulating those assumptions, thus making them available for conscious reflection and questioning. This reflective mode has the potential of 
questioning all voices, listening to all voices and probing into all assumptions. A programme of this kind is what I described some time ago under the label of reflection literacy (Hasan 1996). But to be able to encourage reflection literacy those who educate teachers need to rethink the interconnections between the semiotic, the social and the cognitive.

\section{References:}

Berger, P. \& Luckman, T. 1966. The Social Construction of Reality: A Treatise on the Sociology of Knowledge. New York: Doubleday.

Bernstein, Basil. 1971. Class, Codes and Control, Volume 1: Theoretical Studies toward a Sociology of language. London: Routledge and Kegan Paul.

Bernstein, Basil. 1990. The Structuring of Pedagogic Discourse: Volume IV, Class, Codes and Control. London: Routledge.

Bernstein, Basil. 1996. Pedagogy, Symbolic Control, and Identity: Theory, Research, Practice. London: Taylor and Francis.

Carr, Margaret. ????. Developing learning dispositions: A perspective from early childhood education

lang3081.

Claxton, Guy. ????. Education for the learning age: A sociocultural approach to learning to learn.

Cloran, Carmel. 1994. Rhetorical Units and Decontextualisation: An Enquiry into Some relations of Context, Meaning and Grammar. Monographs in Systemic Linguistics, 6. Nottingham University: School of English Studies.

Cloran, Carmel. 1995. Defining and relating text segments: subject and theme in discourse. In On Subject and Theme: A Discourse Functional Perspective, edited by Ruqaiya Hasan \& Peter H Fries. Amsterdam: John Benjamins.

Cloran, Carmel. 1999. Contexts for learning. In ngnp3081 Pedagogy and the Shaping of Consciousness, edited by Frances Christie. London: Cassell.

Hasan, Ruqaiya. 1989. Semantic variation and sociolinguistics. Australian Journal of Linguistics, 9/2 (pp 221-276).

Hasan, Ruqaiya. 1992. Rationality in everyday talk: from process to system. In Corpus Linguistics: Proceedings of Nobel Symposium 82, Stockholm 4-8 August 1991, edited by Jan Svartvik. Berlin: Mouton de Gruyter. 
Hasan, Ruqaiya. 1993. g3081Contexts for meaning. In Georgetown Round Table on Language, Communication, and Social Meaning 1992, edited by James E Alatis. Washington DC: Georgetown University Press.

Hasan, Ruqaiya. 1996. Literacy, everyday talk and society. In Literacy in Societyangfe1033, edited by Ruqaiya Hasan \& Geoff Williams. London: Longmans.

Hasan, Ruqaiya. 1999. Speaking with reference to context. In Text and Context in Functional Linguistics, edited by Mohsen Ghadessy. Amsterdam: John Benjamins. (pp 219-328).

Hasan, Ruqaiya. 2000. The uses of talkgnp3081 . In Discourse and social Life, edited by Srikant Sarangi \& Malcolm Coulthard. London: Longman

Hasan, Ruqaiya \& Cloran, Carmel. 1990. A sociolinguistic interpretation of mother child talk. In Learning, Keeping and Using Language: Selected Papers from the 8th World Congress of Applied Linguistics, edited by M A K Halliday, John Gibbons and Howard Nicholas. Amsterdam: John Benjamins.

Lemke, Jay L. ????. Becoming the village: Education across lives.

Mercer, Neil. ????. Developing dialogue.

Vygotsky, L. S. 1978. Mind in Society: The Development of Higher Psychological Processes, edited by Michael Cole, Vera-John-Steiner, Sylvia Scribner and Ellen Souberman. Cambridge: Harvard University Press.

Wells, Gordon. ????. Enquiry as an orientation for learning: teaching and teacher education.

Wertsch, James V. 1985. (Ed) Culture, Communication and Cognition: Vygotskian Perspectives. Cambridge: Cambridge University Press.

par Williams, Geoff. 1995. Joint Book-Reading and Literacy pedagogy: A SocioSemantic Interpretation. CORE vol 1, 19(3); vol 2, 20(1).

Williams, Geoff. 1999. The pedagogi device and the production of pedagogic discourse: a case example in early literacy education. In Pedagogy and the Shaping of Consciousness1033, edited by Frances Christie. London: Cassell.

\section{Notes:}

i. The conventions for the transcription are as follows:

$\begin{array}{lll}(\mathrm{CAPITALS}) & = & \text { situational comment, based on analyst's listening to audio-recording; } \\ {[? \mathrm{go} \text { away }]} & = & \text { segment not intelligible; best guess on the basis of context; } \\ {[? \quad]} & = & \text { segment unintelligible; co-textual clues insufficient to allow guess; } \\ <<3 \text { abc }>> & = & \text { enclosed message(s), i.e. } 3 \text { interrupts the message surrounding }<<> \\ ? * * & = & \text { no time allowed for response after this question; } \\ \text { abc C } & = & \text { message } a b c \text { left incomplete; } \\ \text { abc .. } & = & \text { a (longer than usual) pause at this point; } \\ * * \text { abc } & & \\ * * \text { def } & = & \text { paired asterisks indicate turn overlap; }\end{array}$

Note that the turns are numbered afresh for each extract. 
idctlparii. This extensive research was funded by the Australian Research Council and by Macquarie University Research Grants. Details of the research design, subjects examined and mode of data collection and analysis can be found in Hasan (1989; 1992; 1993) and Hasan and Cloran (1990).

iii. For a more detailed classification and analysis of cultural activity, see Hasan 1999, on which the present discussion is based.

iv. For a detailed discussion of con/textual shift and its significance for the development of discourse, see Hasan (2000). On how one category of verbal action may be embedded within another, see also Cloran (1994, 1995, 1999).

v. A good example of such pedagogy will be found in the conversational sequences in Mercer (this volume).

81vi. Rosemary is Julian $=\mathrm{s}$ sister.

vii. For more detailed discussions see Hasan 1989, 1992, 1993; Cloran 1994, 1999; Williams 1995, 1999.

viii. On the basis of the preceding dialogue, it would appear that Karen is referring to some sauce.

r 